\title{
Rose: uma ilha de estereótipos em Lost
}

//////////////////I Rogério de Almeida ${ }^{1}$

\section{Christian H. Pelegrini}

1. Doutor em educação pela Universidade de São Paulo. Professor da Faculdade de Educação da USP e pesquisador do Geifec (Grupo de Estudos sobre Itinerários de Formação em Educação e Cultura). E-mail: rogeriodealmeida@gmail.com

2. Doutorando na Escola de Comunicações e Artes da Universidade de São Paulo, professor dos cursos de comunicação social da Pontifícia Universidade Católica de São Paulo e da Universidade São Judas Tadeu e pesquisador do Geifec. E-mail: christian.pelegrini@gmail.com 


\section{Resumo}

Este artigo é resultado de pesquisas realizadas pelo Geifec (Grupo de Estudos sobre Itinerários de Formação em Educação e Cultura) e tem por objetivo a análise das formas de representação da personagem Rose Nadler, da série americana Lost. Mulher, negra, próxima dos 60 anos, acima do peso, Rose está na intersecção de uma série de grupos minoritários, e sua presença na tela incorre na sobreposição de estereótipos pouco comuns na série. O referencial teórico toma por base as contribuições de Mazzara (1998) e Mittell (2010), e a metodologia parte do levantamento das aparições da personagem Rose ao longo das três primeiras temporadas da série, com captura de imagens e transcrição de diálogos.

\section{Palavras-chave}

Estereótipos, personagens secundários, séries televisivas.

\section{Abstract}

This paper is the result of research made on Geifec and has as a goal to analyze the modes of representation of the character Rose Nadler, from the American series Lost. Woman, African-American, close to 60 s, overweight, Rose is in the intersection of a series of minority groups and her presence occurs as an overlapping of unusual stereotypes in the series. The theoretical references use the contributions of Mazzara (1998) and Mittell (2010) and the methodology takes the apparitions of the character in the first three seasons of the series, with images and dialogues transcriptions.

\section{Keywords}

Stereotypes, secondary characters, TV series. 
3. Nota dos editores: fan kingdom; conjunto de fãs de um programa de TV, pessoa ou fenômeno, cuja interação se dá principalmente pela internet.

4. As referências originalmente em inglês e espanhol foram traduzidas pelos autores.

5. Usamos o modelo exposto em Eco, que parte da divisão formalista (russa) e acrescenta a ela a manifestação sígnica da narrativa (em nosso caso, a amplitude de linguagens que caracteriza a transmídia). Ver ECO, 2010, p. 39-40.

\section{Introdução}

São muitos os fatores que tornam Lost um fenômeno importante no universo cultural da última década. Poucos contestariam a afirmação de que a série conquistou um lugar de destaque na história da ficção seriada de TV. Realizadas pela produtora Bad Robot e exibidas originalmente na rede americana ABC entre os anos de 2004 e 2010, as seis temporadas do programa são um importante produto cultural distribuído desde então em escala global na forma de syndication, via web ou como coleções de DVDs e Blu-rays.

Mais que apenas cativar públicos numericamente consideráveis e tirar o fandom ${ }^{3}$ dos guetos digitais, trazendo-os para o horário nobre, Lost catalisou uma série de fenômenos que marcam a transformação da TV e sua adaptação a uma nova ecologia midiática. Para Mittell (2010, p. 49), "a série exemplifica como programas que teriam se restringido a uma audiência de fãs na era das redes podem se tornar de massa através da convergência digital"4.

Alardeada como uma experiência que transcende o televisual (e tipifica as chamadas narrativas transmidiáticas ou narrativas expandidas), Lost acontece como um grande quebra-cabeças a ser desvendado por seu público (CORDEIRO, 2007), com conexões a serem feitas nos três níveis da narrativa: a fábula, o enredo e o discurso 5 .

O universo narrativo de Lost apresenta elementos oriundos de diferentes gêneros (e.g. suspense, ficção científica, policial, romance, comédia etc.), construídos na história e nos arcos dramáticos por 
meio de uma multiplicidade de personagens. Embora a série seja bastante conhecida tanto pelo sucesso de seu texto primário quanto pelas repercussões dos textos secundários e terciários, tomemos algumas linhas para descrever o conteúdo da produção.

No nível da fábula, Lost conta a história de um grupo de sobreviventes da queda do voo 815 da Oceanic Airlines, que ia de Sidney a Los Angeles. Isolados do mundo em uma misteriosa ilha, o que seria uma curta espera por resgate acaba se transformando em uma longa estadia, na qual experimentam interações com grupos humanos hostis e com entes sobrenaturais de todo tipo, além das mazelas da sobrevivência precária e dos conflitos humanos internos que o grupo apresenta.

Em Lost, o protagonismo é exercido por um ensemble casting. Introduzidos na ficção seriada de televisão no final dos anos 70 (CARLOS, 2006, p. 17), os ensemble shows se caracterizam por não acompanhar as ações de um único personagem (ou mesmo uma dupla), mas de um grupo de indivíduos (em geral, sem hierarquização entre eles). Quando o avião cai no episódio piloto, somos informados de que 48 pessoas sobrevivem. No entanto, o desenvolvimento dramático da série ao longo da primeira temporada gravita em torno de 14 sobreviventes (e um cão). As ações iniciais na ilha visam à sobrevivência do grupo e, aos poucos, começamos a saber sobre cada um, sobre suas personalidades e suas histórias pregressas. Como denuncia o cartaz promocional da estreia da série na rede ABC (Figura 1), os 14 personagens são o objeto de interesse.

Esse grupo é composto por Jack Shephard, talentoso cirurgião; James "Sawyer" Ford, malandro golpista; Kate Austen, criminosa fugitiva; Shannon Rutherford, adolescente mimada, meia-irmã de Boone Carlyle, jovem rico; o coreano Jin-Soo Kwon, capanga de um rico empresário e casado com Sun-Hwa Kwon, filha do seu patrão; Charlie Pace, astro de rock decadente e viciado; Hugo "Hurley" Reyes, ganhador da loteria com azar crônico; Sayid Jarrah, ex-soldado da Guarda Republicana Iraquiana; Michael Dawson, empreiteiro de obras e ilustrador amador, pai de Walt Lloyd, garoto de dez anos que acaba de perder a mãe; Claire Littleton, jovem grávida prestes a dar o bebê para adoção; John Locke, ex-funcionário de escritório e paraplégico (que, na ilha, misteriosamente, volta a andar). 


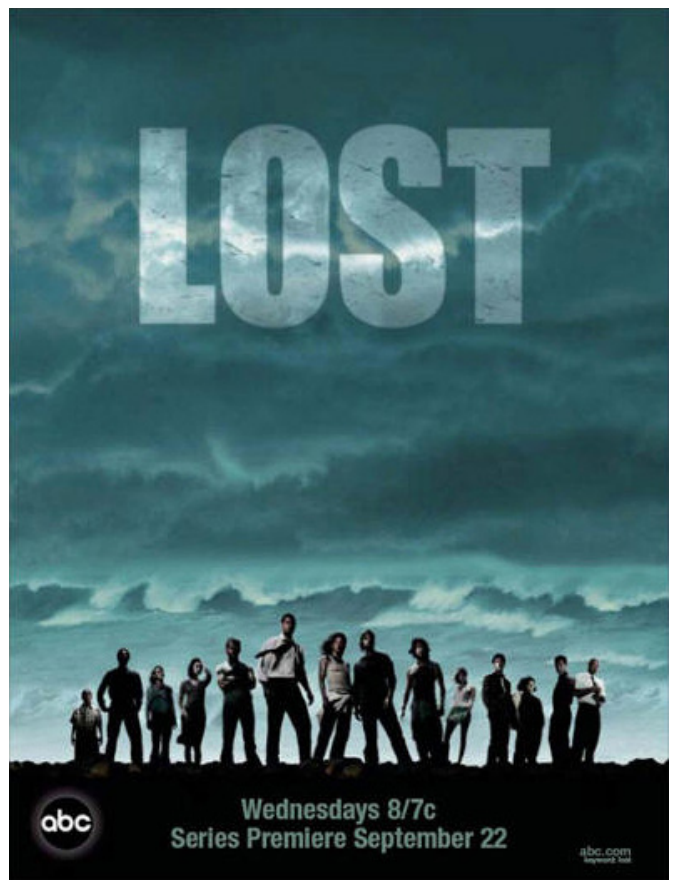

Figura 1: Cartaz promocional de estreia da série na rede americana $\mathrm{ABC}$
Esse grupo de 14 personagens não é o único com função dramática ao longo de toda a série. A cada temporada, personagens saem da história (morrem ou fogem); e outros são acrescidos (outro grupo de sobreviventes é descoberto, um grupo antagonista é apresentado etc.). Além dessa flutuação no elenco principal (que participa mais, com mais falas), ao longo dos episódios, personagens secundários entre os sobreviventes, originalmente relegados ao "fundo" da narrativa, ganham o status de "figura" por algumas cenas ou mesmo episódios, desenvolvendo um arco próprio ou participando de forma mais ativa de um arco de outro personagem, para depois voltar ao extracampo. É esse o caso de nosso objeto, Rose Nadler.

Outra forma de inserção de personagens na fábula é por meio da vida pregressa e futura dos sobreviventes da ilha. Através de analepses e prolepses, conhecemos a vida de cada personagem e os eventos que o levaram ao voo 815 da Oceanic Airlines. Tomamos conhecimento de sua história e de todos os personagens que, de alguma forma, compõem sua trajetória de vida. Conhecemos o pai de Jack e sua ex-esposa; conhecemos o padrasto de Kate e seus comparsas de crime; a família de Hurley e seus antigos companheiros de hospício etc. 
6. Ou round characters; evitamos a tradução personagem redondo por achar a expressão reducionista.
As analepses espalhadas nos episódios das seis temporadas conferem aos personagens mais profundidade, permitindo que o espectador entenda suas motivações e comportamentos, tornandoos um pouco mais densos e complexos, permitindo que cada um seja mais que a aparência imediata, mas personagens profundos ${ }^{6}$ (FISKE, 2011, p. 153). Tais estratégias narrativas adensam o enredo de Lost, revelando que a vida de cada um dos personagens estava, desde antes do acidente, ligada de alguma forma às dos outros. Essa conexão é fatorada pela quantidade de personagens e por toda a gama de relações possíveis.

Lost não é a primeira narrativa a postular essas conexões. Literatura (e.g. Dickens) e cinema (e.g. Iñárritu) já o faziam há muito tempo, afirmando as complexidades da vida e a nossa profunda conexão com tudo e todos. Mas Lost o fez com um número de personagens (logo, de conexões) muito maior; e saliente-se que o fez exibindo tal complexidade para grandes públicos e em horário nobre.

\section{A personagem Rose Nadler}

Rose Nadler é interpretada por L. Scott Caldwell. Ela é uma atriz negra, nascida em 1950, formada em Theater arts and communications pela Loyola University de Chicago e bastante Figura 2: Rose Nadler frequente em séries de TV americanas.

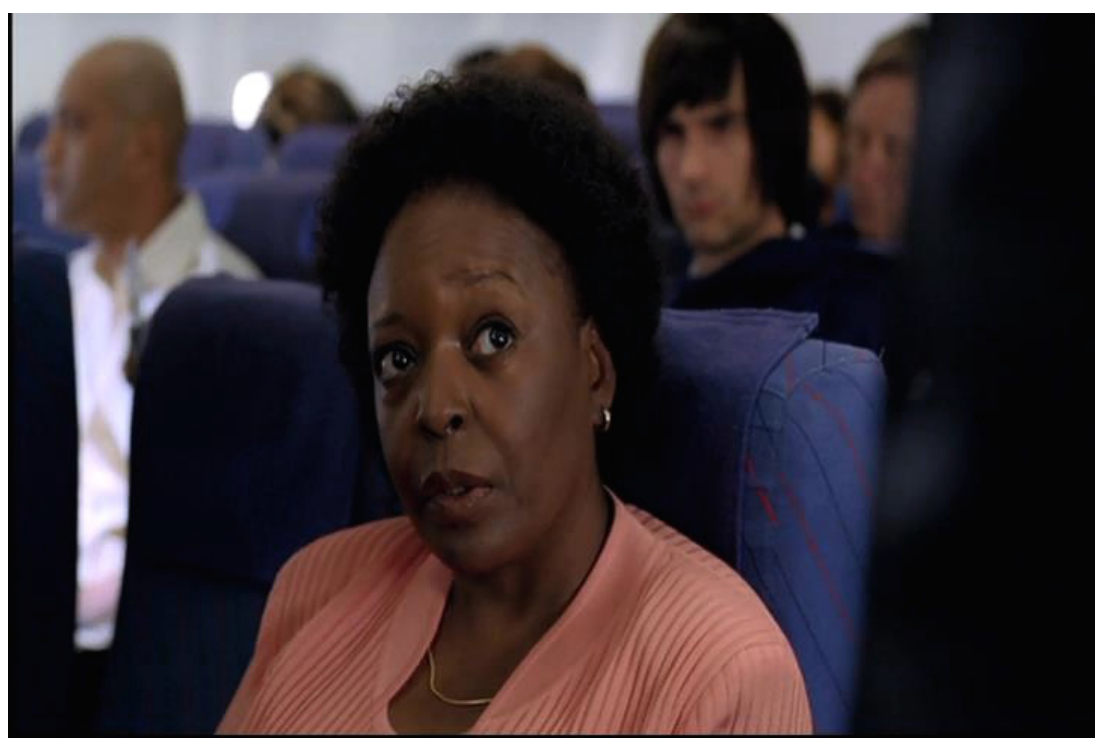


A personagem Rose é mostrada em sua vida pregressa como gerente de escritório. Conhecera seu marido Bernard, dentista, quando ele a ajudou a desatolar seu carro durante uma nevasca. Já bastante maduros, iniciam um relacionamento que culmina no pedido de casamento de Bernard. Nesse momento, Rose lhe confessa que tem uma doença terminal e poucos meses de vida. Bernard mantém o pedido, e eles se casam. Bernard, desesperado pela iminência da perda de Rose, a leva a um curandeiro australiano. Na consulta, Rose é avisada de que o curandeiro não pode fazer nada por sua condição, mas que sua cura se encontra “em outro lugar". Ao retornarem da Austrália, tomam o fatídico voo 815. No momento do acidente, Bernard está na área de trás do avião (no toalete). Essa parte da fuselagem cai em outra região da ilha (os espectadores só ficam sabendo do outro grupo de sobreviventes na segunda temporada; até então, não há qualquer indicação da sobrevivência de Bernard).

Nas primeiras cenas do episódio "Piloto, parte 1" (o primeiro da temporada 1), já na praia, após o acidente, Rose é ressuscitada pelo médico Jack Shephard. Mais tarde, quando a ilha começa a dar mostras de suas ameaças, o grupo ouve pela segunda noite sons aterrorizadores vindos da floresta. Ao escutarem os sons, é a personagem Claire, franzina e nos estágios finais da gravidez, que se aproxima, com um misto de curiosidade e apreensão, para tentar ver o que se passa. Claire tem um gestual expansivo e resoluto. Rose, nesse momento ainda abalada pelos acontecimentos, mantém os braços cruzados, protegendo-se do frio da chuva que cai, imobilizada em sua posição. Enquanto Claire questiona sobre o que seriam os sons que vêm da floresta, Rose é lacônica e emocional: "Que horror!".

Enquanto os personagens buscam cuidar dos feridos, construir abrigos e encontrar alimentos, Rose se resume a uma mulher em choque, incapacitada pelo abalo psicológico. É mostrada por dias sentada na beira da praia, olhando o horizonte e sendo objeto de piedade dos demais personagens.

No episódio Walkabout (o quarto da temporada 1), Jack vai até Rose para oferecer consolo. Sua atitude recebe de Rose 
uma peculiar avaliação de caráter: "Você tem uma índole boa. Uma boa alma. Acho que foi por isso que quis ser médico". $\mathrm{Na}$ continuação da cena, quando Jack avisa que cremarão os mortos do acidente e convida Rose para dizer algumas palavras e se despedir de seu marido, Bernard, ela mais uma vez deixa manifesta sua (convicta) intuição:

Jack: "Talvez você queira dizer algumas palavras... sabe... sobre seu marido..."

Rose (intrigada): "O quê?"

Jack: "Eu disse que se quiser dizer adeus ao Bernard..."

Rose (como se dissesse algo evidente): "Doutor, meu marido não está morto".

Rose volta a ficar no "fundo" do elenco. Aparece pouco em planos fechados e não tem falas. Mas sua manifestação não permanece estática ao longo da série. Aos poucos, passado o abalo causado pelo acidente, Rose vai se recuperar e assumir uma postura diferente: vai de alguém “a cuidar” para alguém que cuida - ela assume uma postura maternal em relação aos demais personagens.

Volta a se destacar em Whatever the case may be (temporada 1, episódio 12), dessa vez mostrada com mais ânimo, bastante integrada aos esforços do grupo para construir uma nova normalidade para os sobreviventes. Oscilando entre a resignação e o otimismo, Rose está tão melhor que pode estender a mão e ajudar outro personagem de forma muito específica.

Quando Claire é raptada, Charlie, relativo par romântico da moça, falha em lhe oferecer segurança, sendo deixado "para morrer" enforcado em uma árvore. Abalado pela sensação de fracasso, ouve de Rose palavras de consolo, que o eximem da culpa pelo ocorrido. Termina sua fala com uma frase solidária: "Sabe o que eu acho, Charlie? Precisa de ajuda". Ao que Charlie responde: "E quem vai me ajudar?". A cena corta para o plano de uma cruz fincada em uma cova improvisada. A cena da cova é de 
outro arco dramático, com outros personagens, mas já indica o teor do retorno de Rose no mesmo episódio.

Procurada por Charlie na mesma noite, Rose reitera suas convicções.

Charlie: "Seu marido estava na parte de trás do avião?"

Rose: "É. Ele estava sim. Mas ele ainda vai voltar".

Charlie: "Acha que ele está vivo?"

Rose: "Tenho certeza".

Charlie: "Como?"

Rose: "Simplesmente sei. O limite entre a fé e a rejeição é muito tênue [pausa]. É muito melhor do lado de cá”.

A cena continua com Charlie extravasando seu sofrimento pela ausência de Claire. Chorando, balbucia a Rose: "Ajude-me”. Ao que Rose responde: "Querido, não sou eu quem pode te ajudar". Rose segura a mão de Charlie, olha para o alto e inicia uma oração: "Pai do céu, nós lhe agradecemos..." A câmera sobe, acompanhando as palavras de Rose e acentuando a direção de seu olhar. Há, nesse ponto, mais uma vez, um afastamento de Rose dos arcos dramáticos do grupo principal de personagens. Ela volta a ganhar destaque na segunda temporada.

Em Everbody hates Hugo (temporada 2, episódio 4), a representação de Rose ganha contornos ainda mais dignos de observação. A primeira cena do primeiro bloco se inicia com um travelling lateral que acompanha um improvável varal estendido na praia. No final do movimento (e no final do varal), encontramos Rose, alguns dias depois de sua última cena com Charlie, estendendo roupas. Pega o “cesto" e retorna a um improvisado tanque de roupas. 
Figura 3: Rose enche o varal com roupas lavadas...

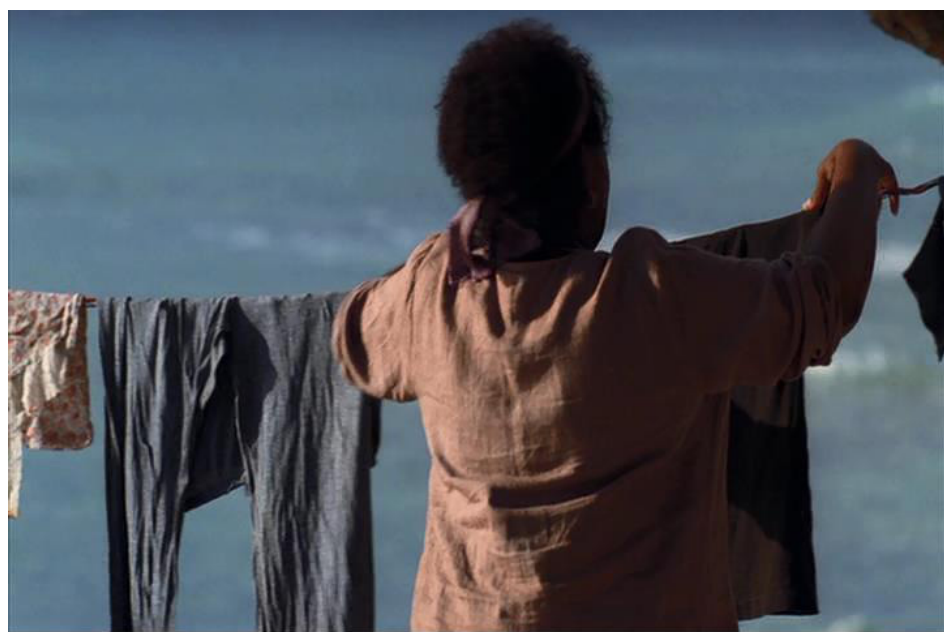

Figura 4: ...pega o cesto de roupas e...

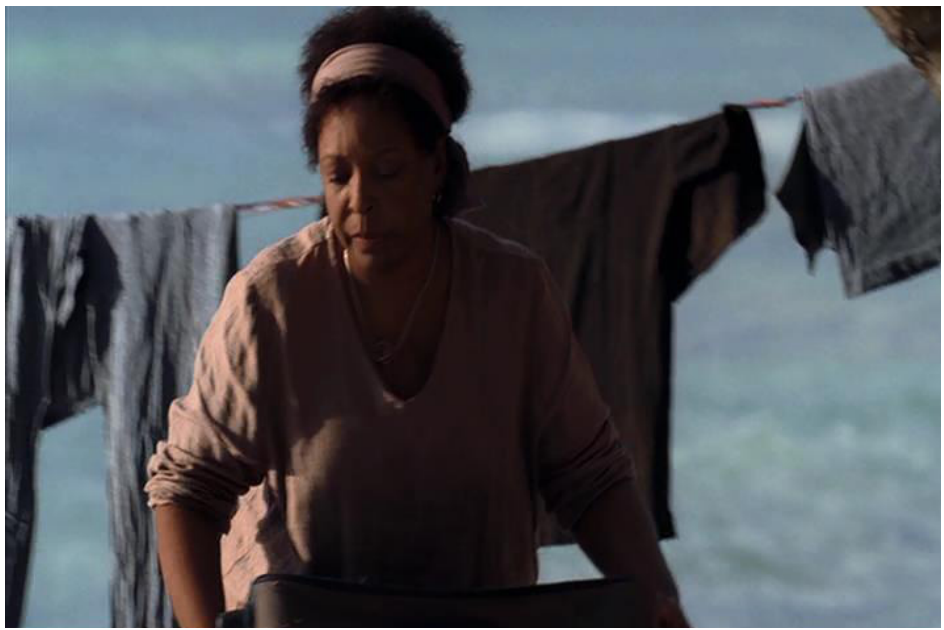

Figura 5: ...lava mais um cesto de

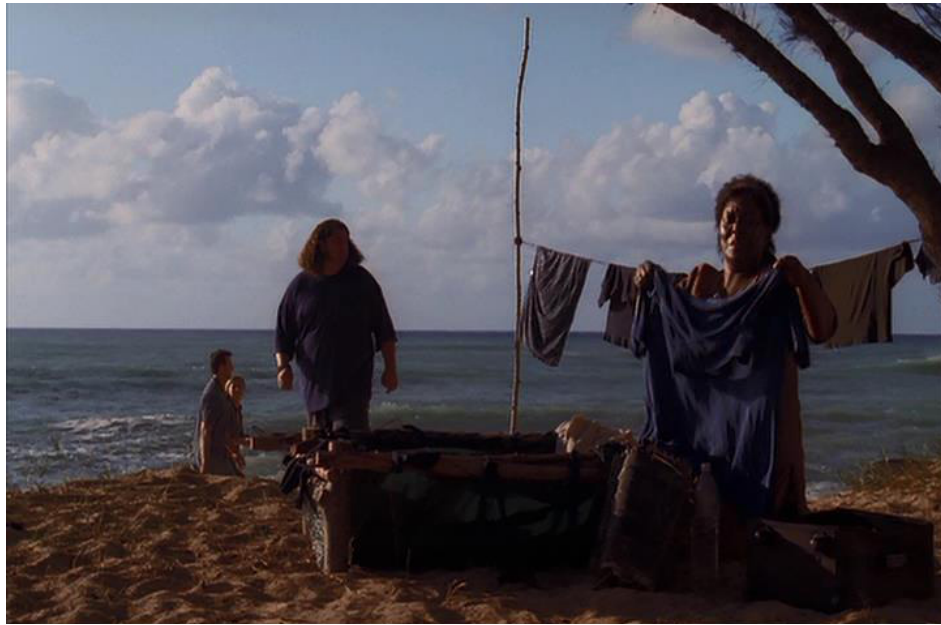
roupas sujas... 
Rose cantarola quando recebe a visita de Hurley (o Hugo do título), que tenta assimilar os eventos acontecidos nos últimos episódios: a descoberta de um antigo bunker cheio de alimentos e recursos de todo tipo, além dos usuais mistérios e das crises recentes pelas mudanças de equilíbrio de poder entre os personagens principais. Hurley, na verdade, busca alguém confiável para ajudá-lo a inventariar os recursos recémdescobertos. Transcrevemos o diálogo:

Hurley: "Oi, Rose".

Rose: "Oi, rapaz”.

Hurley: "E aí? Tá lavando uma roupinha?"

Rose: "Pois é, estou mesmo. Você pode me passar aquela roupa suja ali, por favor?”

Hurley dá a ela mais um "cesto" de roupas sujas.

Rose: "Obrigada".

Hurley: "Não quer saber o que aconteceu?"

Rose: "Sobre o quê?"

Hurley: "Lá na selva. Todo mundo me pergunta da escotilha".

Rose: "Isso é coisa sua, querido".

Hurley: “'Cê’ não quer saber?”

Rose: "Olha, seja lá o que for, não vai me ajudar a lavar essa roupa toda, não é?"

Hurley: "Bom, na verdade, pode ajudar".

A fala de Hurley desperta o interesse de Rose. Apresentada ao bunker, Rose ajuda Hurley no inventário. Transcrevemos parte do diálogo:

Hurley: "Iniciativa Dharma, molho para salada sabor ranch. [pausa] Parece gostoso". 
Hurley pega uma pilha de caixas e dentro encontra dezenas de barras de chocolate.

Hurley: "Chocolate Apollo. Conhece essa marca?"

Rose: “Não. Mas 'doce é doce', é o que Bernard sempre disse. E, por falar em doce, aquele homem é louco por doce o tempo todo".

Hurley: "Bernard era seu marido?"

Rose: "É o meu marido".

Hurley: "Ah. Mas eu achei que ele tava na traseira do avião. Humm. Desculpa, eu não quis ser...”

Rose: "Não, tudo bem. Não tem problema. O Bernard está bem. Eu sinto isso. Vamos ao atum em lata?"

Esse também é o episódio em que é apresentado formalmente o marido, Bernard. Quando os personagens Michael, Sawyer e Jim são capturados pelo recém-descoberto grupo de sobreviventes da cauda do avião, um homem se aproxima do grupo. Ele é branco, em torno dos 60 anos. Pergunta aos prisioneiros se em seu acampamento há uma mulher chamada Rose. Sawyer responde: “Uma negra? Uns cinquenta anos?". Bernard confirma e fica sabendo que Rose está bem.

Rose é mostrada novamente lavando roupas. No episódio "Abandoned" (o sexto da temporada 2), dessa vez divide a tarefa com Hurley. Quando ele a questiona sobre o porquê de estarem pendurando roupas no varal quando o bunker tem uma secadora elétrica, Rose revela, não sem ironia, certa abnegação em relação às tarefas: "Quem precisa de uma secadora quando tem o sol e ar fresco? A gente corre o risco de ficar mimado, não é mesmo?”

Em “Collision” (temporada 2, episódio 8), Rose recebe Jack, que há muito não saía do bunker, carregando uma travessa de frutas, oferecendo-lhe um lanche saudável (e o repreendendo por falar de boca cheia). O episódio "S.O.S." (temporada 2, episódio 19) é o que mais mostra Rose e Bernard, incluindo-se aí sua vida pregressa. Vemos Bernard ajudando Rose a desatolar 
seu carro da neve. Acompanhamos o pedido de casamento e a revelação sobre o câncer. Vemos o casal procurando o curandeiro e entrando no voo 815.

Quando seu já ambientado marido Bernard tem a iniciativa de reunir voluntários para construir um grande sinal de socorro na praia, Rose é a única a questionar a ação de Bernard.

Rose: "Eu acho melhor a gente falar com o Jack antes de fazer isso".

Bernard: "Mas pra que pedir a aprovação do Jack? Ele não é o presidente. Ele é só um médico”.

Rose: "E você é dentista".

O grupo que ouvia Bernard ri discretamente. Rose se mostra reticente a buscar uma saída da ilha. Ao final do episódio, na cena em que Rose busca a conciliação com o marido, ela lhe aparece na praia, carregando seu jantar. Quando revela a Bernard que o curandeiro australiano não pudera curá-la, Rose também afirma saber que seu câncer desaparecera por causa da ilha. Bernard a questiona sobre como pode saber isso. Rose é enfática e lacônica: "Confie em mim. Eu sei".

Essas não são as únicas aparições de Rose nas duas primeiras temporadas da série. Mas as outras são bem curtas e, em geral, ligadas aos arcos de outros personagens. As cenas selecionadas aqui têm Rose como personagem de destaque e serão usadas na análise dos estereótipos.

\section{Rose e os estereótipos em Lost}

Nas palavras de Mittell (2010, p. 305), ao falar da TV na cultura americana,

televisão não apenas define as normas culturais sobre democracia e diferenças de classe na América mas também afirma o que significa ser mulher, latino ou gay, todos considerados como parte de um senso mais amplo de política cultural. 
Embora não se possa aceitar que a TV seja o único fator a definir as normas culturais, sua força é inegável, e Lost não deixa de representar e retomar expectativas acerca de categorias de identidade.

Nosso interesse no que diz respeito à personagem Rose Nadler é observar como se dá sua representação na TV e apontar o quanto ela reitera expectativas construídas culturalmente sobre o que é ser mulher, negra e idosa. Em outras palavras, Rose ocupa o lugar da representação estereotípica.

Mittell (2010, p. 309) define estereótipo como "limitadas, supersimplificadas e imprecisas definições de identidade cultural". Nesse sentido, a representação de indivíduos se reduz a um mero coletivo de características, anulando toda a riqueza e diversidade existentes entre os indivíduos pertencentes ao mesmo grupo. Por outro lado, Mazzara, num esforço para recobrir toda a complexidade do fenômeno, resgata as origens da expressão no universo da tipografia e de sua introdução nas ciências sociais pelo jornalista Walter Lippman, para quem

\footnotetext{
a relação cognitiva com a realidade externa não é direta, mas se realiza através de imagens mentais que cada um forma dessa realidade e, portanto, está fortemente condicionada pela imprensa, que então estava assumindo conotações modernas da comunicação de massas. Segundo Lippman, essas imagens mentais, que constituem uma espécie de pseudoambiente com o qual se interage, têm a característica de serem frequentemente simplificações grosseiras e muito rígidas (isto é, estereótipos) (MAZZARA, 1998, p. 16).
}

Obviamente o contexto em que fala Lippman evoluiu para assimilar outras mídias, TV inclusive. Mazzara (1998, p. 16) vai além, ao propor delimitar o sentido de estereótipo de modo a instrumentalizar suas análises: "Neste livro [...] consideramos o estereótipo como um conjunto coerente de crenças negativas que um certo grupo compartilha acerca de outro grupo ou categoria social". Assim a estereotipia é necessariamente negativa. Também 
fica evidente que o termo se volta para grupos sociais. E é essa a definição que deve nortear nosso estudo de Rose Nadler.

Iniciemos nossa análise considerando questões de gênero. Mazzara (1998, p. 20) afirma que o domínio dos homens sobre as mulheres persiste, a despeito de discursos libertários e da correção política emulada em muitas sociedades. Assim, a mulher continua relegada a uma condição subalterna, concretizada, em Rose, de inúmeras formas. Para começar, ela parece ter uma existência fortemente condicionada à do marido. Desde o início da narrativa, as falas e ações de Rose versam predominantemente sobre a esperança de retorno de Bernard. Ela não faz muito além disso. Enquanto outros personagens atuam numa multiplicidade de objetivos, Rose parece se resumir a uma esposa sem o marido. Ao reencontrar Bernard, ambos passam a ser um só. Rose Nadler se torna parte de "Rose e Bernard". E a dinâmica de casal reitera relações de gênero em que a insurgência da esposa é vista como evento cômico pelo grupo, ao contrariar expectativas de submissão. Representativo disso é que, mesmo nas manifestações da efervescente fandom de Lost, Rose não é usualmente referida sozinha. Ela é sempre parte do casal "Rose e Bernard".

Mas não é só na relação com o marido que Rose atualiza estereótipos femininos. Suas ações e falas ecoam muitas construções culturais acerca do gênero. Para Mazzara (1998, p. 20):

\footnotetext{
Em compensação, segue recaindo sobre a mulher a maior parte do peso da criação dos filhos, do cuidado com os idosos e, em geral, da condução da família, segundo a mais clássica divisão de funções: para o homem, a produção e a competição; para a mulher, a atenção com a casa e a reprodução da vida.
}

Para Mittell (2010, p. 334), “outro par de tropos de gênero corresponde ao da divisão de profissão/domesticidade: masculinidade é tipicamente mostrada como sendo racional, enquanto feminilidade é emocional". 
E Rose atualiza tais representações o tempo todo. De sua reação ao "som misterioso" que vem da selva ("Que horror!") à sua sensibilidade exacerbada, que a deixa em choque, imobilizada por dias. Outra forma como Rose atualiza o estereótipo da mulher emocional é na força de sua intuição. Quando todas as probabilidades contradizem a possibilidade de mais pessoas terem sobrevivido à queda do avião, Rose expressa saber que Bernard está vivo; conhecimento manifestado em diversas oportunidades. Tal convicção não se apoia em absolutamente nada racional, mas tão somente em sua intuição. Da mesma forma, ao contar ao marido que está curada, repete a convicção na intuição.

Nesse sentido, vale a aproximação de Rose com outras personagens negras, também mulheres e de idades semelhantes, que desempenham o mesmo papel quanto aos poderes intuitivos, caso de Oracle, do filme Matrix, interpretada por Gloria Foster, e Oda Mae Brown, interpretada por Whoopi Goldberg em Ghost. São personagens que guardam traços estereotípicos, uma simplificação caricatural que alude a uma base arquetípica (CAMPBELL, 1993), como o da sacerdotisa de sociedades ditas primitivas. Descolados de suas origens e contextos, esses estereótipos se valem da associação do mistério da fertilidade feminina à própria natureza, ou mãe-natureza; daí o caráter maternal, intuitivo e, de certa forma, misterioso dessas personagens.

É o caso de Rose, que também assume uma postura materna em muitos momentos. Tão logo recupera o equilíbrio emocional, ela conforta alguns personagens em momentos de crise (Charlie, Hurley), cuida de outros (as frutas para Jack) ou mesmo reforça a necessidade "dos bons modos", ao pedir que Jack não fale de boca cheia.

Rose também manifesta uma tendência mais passiva que ativa diante dos fatos. Sua inação reitera a dinâmica preponderante na TV, segundo a qual "masculinidade é definida como ativa, enquanto feminino é visto como passivo" (MITTELL, 2010, p. 337). Rose não se interessa em saber sobre a escotilha (quer apenas lavar sua roupa), não se engaja nos esforços do marido para construir o S.O.S. na praia. Não parece mesmo ter interesse sobre a marca do chocolate achado por Hurley. 
É verdade que se pode interpretar o não engajamento de Rose na construção do S.O.S. por sua crença de que se curou de seu câncer por estar na ilha, razão para não querer retornar a casa e à doença. No entanto, de qualquer modo, ainda que se mostre ativa na defesa de sua posição, de seu desejo, a base de sua ação é a intuição.

Além de mulher, Rose é uma pessoa quase idosa. Isso também mobiliza uma série de expectativas acerca de como idosos se comportam e devem ser tratados. Para Mazzara, idosos

são considerados como mentalmente rígidos, orientados ao passado e sem projetos para o futuro, pouco dispostos à novidade; mas também obstinados, coléricos, suscetíveis, pouco adaptáveis, com tendência à vitimização, exigentes e com uma contínua e excessiva necessidade de assistência (MAZZARA, 1998, p. 38).

No episódio "Piloto", quando ouve o som assustador que vem da floresta, Rose se mostra imobilizada, inerte atrás de Claire, espantada com os eventos sobrenaturais, sem empreender nenhuma reação. Ao longo dos episódios iniciais, Rose é objeto de piedade e cuidados por parte dos outros personagens (embora todos estivessem em situação precária e abalados pela queda). Também merece menção que não há, na relação de Rose e Bernard, qualquer traço de amor sensual, mesmo a queda tendo acontecido quando os dois estavam casados havia apenas alguns meses. Assim, o casal idoso se ama, como atestam os olhares carregados de amor que trocam em diferentes momentos na ilha, mas não dá qualquer mostra de vida sexual. Tal característica parece ser comum na representação dos idosos na TV.

Também é interessante observar que, até a terceira temporada, Rose é a única personagem que é mostrada rezando. Mesmo o personagem muçulmano, Sayid, aparece prostrado em direção a Meca em uma única cena, na segunda temporada. Mas Sayid é visto rezando nos instantes iniciais da cena, e tem sua prece interrompida por outros personagens que lhe chamam a atenção para perigos iminentes (um trecho de alguns frames). A oração, 
na cena de Sayid, é uma atividade sem função dramática; não é o elemento central da cena, mas algo que se passa quando a cena se inicia. Para Rose, no episódio "Whatever the case may be" (temporadal, episódio 12), a visibilidade da oração é diferente. É uma ação com funções dramáticas explícitas, carregada de carga emocional para fechar o episódio.

É interessante observar que a cena em que Rose reza remete em muitos aspectos às imagens de igrejas protestantes americanas e aos típicos coros gospel. Esse elemento reitera uma forma de expressão religiosa ligada aos negros americanos. E o olhar sobre essa imagem nos remete ao que há de estereótipo na representação dos negros na personagem de Rose.

De todos os personagens da ilha (do total de sobreviventes), Rose está entre os poucos que são mostrados executando "tarefas" menores. O enredo mostra personagens variados executando tarefas. Desde os cuidados médicos de Jack a quem precise até as tarefas esporádicas que revelam talentos inesperados de Locke: tais atividades se inserem nos esforços de sobrevivência do grupo. Mesmo o casal oriental, Jin e Sun, quando apresentados cultivando uma horta (Sun) ou demonstrando grande habilidade em pescaria (Jin), acabam por exercer atividades que são fundamentais para a sobrevivência na ilha e para a manutenção do enredo. Suas tarefas, embora simples, são essenciais. As de Rose, não. Rose lava roupas.

As improváveis cenas com varais e tanques de roupa(!) exigem que nos perguntemos o porquê de Rose ser a única mostrada dessa forma. Outras personagens aparecem, ao longo da série, torcendo peças de roupa. No caso de Kate e Sun, ambas aparecem "banhando-se" na praia ou em rios. O torcer da roupa é um pretexto para exibir os músculos flexionados e revelar as formas reiterando a mulher como objeto admirável aos olhos masculinos (MITTELL, 2010, p. 340). Assim, torcer uma peça de roupa não é o teor dramático da cena, mas algo que compõe seu banho devidamente mostrado em generoso enquadramento que contenha o corpo todo (MAZZARA, 1998, p. 20). Em última instância, Sun e Kate lavam a própria roupa. 
Rose não lava a própria camisa enquanto se banha. Não torce uma roupa enquanto discute com outros personagens sobre o futuro de todos na ilha. Ela aparece como uma lavadeira. Rose carrega cestos de roupa lavada e preenche varais com elas. Em seguida, volta ao tanque e lava mais roupas.

A improvável cena (repetida quando Rose afirma prescindir de secadora elétrica quando tem "o sol e ar fresco") mostra uma mulher negra sistematicamente lavando roupas que claramente não são suas. Se observarmos a Figura 5, é evidente que a camiseta que Rose lava pertence a Hurley (aliás, é idêntica a que Hurley usa na mesma cena). Rose cantarola feliz enquanto executa tais tarefas, deixando claro no diálogo que só o que lhe interessa é lavar a roupa - Rose não sabe e não quer saber.

Não é a única tarefa executada por Rose na ilha. Em diversas situações, ela aparece servindo outros personagens (chegando a carregar bandejas improvisadas). Quando Rose aparece servindo comida aos personagens principais ou "lavando roupa para fora", agrupa-se à imagem da serviçal, da criada, quase sempre negra (em algumas variantes, latina), repetindo a imagem de Mammy de E o vento levou.

\section{Uma ilha de estereótipos}

Lost tem uma série de méritos no processo de elaboração de sua dramaturgia. Ao fazer uso das prolepses e analepses e mostrar tanto a vida pregressa quanto a futura dos personagens, permite adicionar nuances de motivação e complexidade a suas dimensões subjetivas, nem sempre tão comuns na tradição da ficção seriada em TV. Saber do passado e do futuro permite perceber que nem todos são bons o tempo todo; nem todos são maus indefinidamente. Não há, em Lost, o maniqueísmo do herói e do vilão; tampouco os personagens são unicamente personagens-tipo reciclados do repertório da cultura pop. Assim, personagens se sacrificam e traem, salvam e matam, se resignam e perseveram.

E, em geral, tal riqueza também se reflete na forma como grupos são mostrados na história. As mulheres não são todas iguais; 
os negros não são todos iguais, orientais não são todos iguais. Assim, respeitando a história de cada personagem, Lost consegue desconstruir muitas expectativas baseadas em estereótipos para seus personagens. Quando considerado o elenco principal (os 14 que o cartaz de estreia mostra), e mesmo quando tomados os personagens acrescentados na segunda temporada, são poucas as possibilidades de crítica sobre a representação dos grupos (mulher, idoso, negro etc.).

Os negros do elenco, Michael, Walt, Mr. Eko e Rose, não têm nada em comum. Idem quando se considera o grupo de mulheres (Claire, Shannon, Sun, Kate, Ana Lucia e Libby). Aliás, é digno de menção que todas as mulheres em Lost são muito fortes, ativas, corajosas e mesmo racionais; com exceção de Rose. Bernard e John Locke são os personagens que mais se aproximam da idade de Rose. Nesse caso, enquanto Bernard é bem diferente de Rose, John Locke chega a ser a mais perfeita antítese (a despeito da idade).

Talvez por isso o caso de Rose apareça tanto. O que se observa ao assistir a Lost é que diferentes características que construíram historicamente os estereótipos de mulheres, negros e idosos convergiram para seu personagem. Enquanto o elenco principal é rico e complexo, Rose parece ter sido construída com sobras de uma televisão do passado; fruto de uma desatenção à edificação do personagem.

Sabemos que Rose era gerente de um escritório, cargo que demanda certa capacidade administrativa e considerável proatividade. Mas isso se esvai em sua estadia na ilha. Vemos com certa desconfiança que ela se exime de qualquer responsabilidade ou interesse de participar ativamente nos rumos que o grupo toma, tornando-se naturalmente alguém “comandada”. Não há necessariamente um problema em vermos alguém lavando roupas para o grupo. Mas fora da ilha o predomínio dos negros nos papéis de serviçais tem raízes históricas na dominação e exclusão étnicas. Na ilha, a ordem social "zera” (ou, ao menos, deveria zerar). Todos são sobreviventes de um acidente de avião. Nesse contexto, não há justificativa para que a única pessoa a lavar roupas dos outros seja uma mulher negra. 
Não se trata aqui de acusar a série de induzir ideologicamente os espectadores a uma possível naturalização do papel desempenhado por Rose, generalizando-o para toda a sociedade. Como bem demonstrou Bosi (2010), não convém buscar uma ideologia escondida nas obras de ficção, como se seus criadores fossem ideólogos mal intencionados e, portanto, suspeitos. Os demais personagens da ilha desmentem qualquer tentativa reducionista quanto a isso. Trata-se, sim, de reconhecer que Rose apresenta traços estereotipados, que condizem mais com o fato de ser uma "personagem secundária", portanto sem a mesma profundidade que dos protagonistas. Talvez por isso tenha catalisado, para si, os traços estereotípicos que apontam, eles sim, para um olhar ideologicamente construído e estabilizado na sociedade norte-americana.

\section{Considerações finais}

Quando tomado o êxito de Lost no universo da ficção seriada em $\mathrm{TV}$, nas ramificações transmidiáticas e no universo da cultura pop em geral, é claro que seu texto continuará a ser recebido por muito tempo e em muitos lugares. Nesse sentido, a importância da forma como personagens são representados em sua narrativa é diretamente proporcional à sua participação na vida cultural de seus espectadores.

Cabe, portanto, reiterar que os êxitos vão além de um elenco multiétnico, mas estão também na própria construção dramática de seus personagens e na explicitação da complexidade que forma um ser humano. Vemos mulheres fortes e corajosas (Kate, Juliet), esposas que não se rendem ao domínio marital e assumem papel ativo na condução do casamento e em sua própria vida (Sun). Vemos personagens negros com histórias variadas e pouco estereotipadas. E, entre os idosos retratados na história, a maioria se mostra proativa e segura de seu caminho.

A exceção parece ser Rose. Ela acaba por se constituir como uma ilha de estereótipos, alguns bastante grosseiros. E o risco é identificarmos um personagem secundário (como Rose) com a "pessoa comum", em oposição aos "especiais" ou "escolhidos", e ratificar que não ser um estereótipo é reservado aos melhores da espécie humana, não às pessoas comuns. 


\section{Referências}

BOSI, A. Ideologia e contraideologia. São Paulo: Companhia das Letras, 2010.

CAMPBELL, J. O herói de mil faces. São Paulo: Cultrix; Pensamento, 1993.

CARLOS, C. S. Em tempo real: Lost, 24 Horas, Sex and the City e o impacto das novas séries de TV. São Paulo: Alameda, 2006.

CORDEIRO, T. "Lost e o fim da TV”. Superinteressante, abr. 2007, Disponível em: <http://super.abril.com.br/superarquivo/2007/ conteudo_486660.shtml>. Acesso em: 2 jan. 2013.

ECO, U. Seis passeios pelos bosques da ficção. São Paulo: Companhia das Letras, 2010.

FISKE, J. Television culture. New York: Routledge, 2011.

MAZZARA, B. M. Estereotipos y prejuicios. Madrid: Acento Editorial, 1998.

MITTELL, J. Television and American culture. New York: Oxford University Press, 2010.

\section{Referências audiovisuais}

LOST, episódio "Piloto: parte 1", de J. Lieber, J. J. Abrahns e D. Lindelof (ABC), EUA, 2004.

LOST, episódio “Piloto: parte 2", de J. Lieber, J. J. Abrahns e D. Lindelof (ABC), EUA, 2004.

LOST, episódio "Walkabout”, de David Fury (ABC), EUA, 2004.

LOST, episódio "Whatever the case may be", de D. Lindelof e J. Johnson (ABC), EUA, 2004.

LOST, episódio "Everbody hates Hugo", de E. Kitsis e A. Horowitz (ABC), EUA, 2005. 
LOST, episódio “Abandoned”, de E. Sarnoff (ABC), EUA, 2005.

LOST, episódio "Collision", de J. Grilo-Marxuach e L. Dick (ABC), EUA, 2005.

LOST, episódio “S.O.S.”, de S. Maeda e L. Dick (ABC), EUA, 2005. 